\title{
ANALISIS KEPUASAN MAHASISWA TERHADAP KUALITAS PELAYANAN TENAGA ADMINISTRATIF DI FAKULTAS FARMASI UNIVERSITAS AHMAD DAHLAN YOGYAKARTA
}

\section{ANALYSIS OF STUDENT SATISFACTION SERVICE QUALITY IN PHARMACY FACULTY UNIVERSITY OF AHMAD DAHLAN YOGYAKARTA}

\author{
Ana Hidayati ${ }^{1}$, Achmad Fudholi ${ }^{2}$, Sumarni ${ }^{3}$ \\ ${ }^{1}$ Fakultas Farmasi Universitas Ahmad Dahlan \\ Jl. Prof.Dr. Soepomo SH, Yogyakarta, Telp. (0274) 379418 \\ ${ }^{2}$ Fakultas Farmasi Universitas Gadjah Mada \\ Sekip Utara Yogyakarta 55281 Telp: (0274) 542907 \\ ${ }^{3}$ Bagian Kedokteran Jiwa Rumah Sakit Sardjito \\ Jl. Kesehatan No. 1 Sekip Yogyakarta 55284 \\ Email: ana.hidayati@pharm.uad.ac.id
}

\begin{abstract}
ABSTRAK
Telah dilakukan pengukuran kepuasan mahasiwa ini dilakukan dengan observasi populatif dan pengumpulan data secara prospektif pada mahasiswa tingkat ke empat Fakultas Farmasi Universitas Ahmad Dahlan. Tujuan pengukuran ini untuk mengetahui gambaran kepuasan mahasiswa serta mengetahui peringkat gap yang muncul dari pengukuran dimensi servqual. Diperoleh hasil secara umum bahwa elemen pelayanan di Fakultas Farmasi yaitu karyawan belum memberikan kinerja sesuai dengan harapan mahasiwa yang ditandai dengan rentang nilai masing-masing gap tidak ada yang mendekati ideal yaitu nol (0). Nilai gap dari karyawan pada pelayanan pendidikan pada dimensi Berwujud (tangibles) dengan nilai gap -0,90, Keandalan (reliability) dengan nilai gap 0,90 , Jaminan (assurance) nilai gap -0,90, Empati (empathy) dengan nilai gap -1,10 dan Daya Tanggap (responsiveness) dengan nilai gap -1,10. Sehingga disimpulkan bahwa pelayanan yang diberikan karyawan kepada mahasiswa belum memenuhi harapan mahasiswa.
\end{abstract}

Kata kunci : kepuasaan, kualitas pelayanan Fakultas Farmasi

\begin{abstract}
Student satisfaction measurement has been done with populatif observation and data collected prospectively at the fourth level students of the Faculty of Pharmacy Ahmad Dahlan University. The purpose this study to describe and determine student satisfaction ratings gap that arises from servqual. The results obtained indicate generally that the service element in the Faculty of Pharmacy is namely employees has not given in accordance with the expectations of student performance is characterized by a range of values of each gap there is nothing close to the ideal of zero (0). Gap values of employees in the education ministry on Tangible dimensions with a gap value $-0,90$, Reliability with the gap value -0,90, Assurance gap value -0,90, Empathy with the gap value $-1,10$ and Responsiveness to the value gap $-1,10$. While the reliability of the employee dimension into the first
\end{abstract}


rank and dimensions of responsiveness on the faculty is considered the most excellent service to students.

Keyword : satisfaction, servqual, Faculty of Pharmacy

\section{PENDAHULUAN}

Lembaga pendidikan merupakan suatu lembaga yang memberikan atau menyelenggarakan pelayanan berupa pendidikan. Lembaga pendidikan diyakini mempunyai tugas yang sangat penting yaitu menyiapkan sumber daya manusia agar mampu bertindak sebagai pembawa perubahan dan pencerahan hidup lebih baik.

Upaya memenuhi keinginan mahasiswa merupakan kunci sukses memenangkan persaingan dan tindakan terbaik yang perlu dilakukan oleh lembaga pendidikan tinggi adalah menggunakan umpan balik dari mahasiswa untuk melakukan perubahan pelayanan. Kesesuaian antara keinginan pelanggan dalam hal ini adalah mahasiswa dan kehendak organisasi pengelola Perguruan Tinggi merupakan syarat penting keberhasilan proses pendidikan di Perguruan Tinggi. Setiap mahasiswa menghendaki kepuasan maksimal dari setiap layanan yang terdapat di lembaga pendidikan, dengan kepuasan maksimal yang didapat oleh mahasiswa akan dapat meningkatkan kualitas pelayanan pendidikan.

Sistem pendidikan yang bermutu adalah pendidikan yang diselenggarakan dengan cara yang sistematis dan konsisten serta berkaitan erat dengan kualitas sumber daya manusia. Hal ini didasarkan pada kenyataam bahwa output (keluaran) dari suatu sistem pendidikan adalah sumber daya manusia yang akan digunakan dalam industri dan pembangunan di suatu daerah atau suatu institusi. Upaya peningkatan kualitas sumber daya manusia dapat dilakukan dengan perbaikan sistem pendidikan yang selanjutnya dapat menghasilkan sistem pendidikan yang bermutu.

Evaluasi diri Program Studi Farmasi Universitas Ahmad Dahlan dilakukan secara bertahap dengan melibatkan seluruh staf akademik, tenaga kependidikan, karyawan, mahasiswa dan stakeholder dibawah pengelolaan suatu tim.Berdasarkan hasil evaluasi diri tersebut diketahui bahwa salah satu kelemahan dari prodi
Farmasi adalah secara kelembagaan "brand image" masih rendah dan belum ada masukan dari mahasiswa mengenai perbaikan kualitas pelayanan yang telah diberikan oleh Fakultas Farmasi.

Atas dasar tersebut Universitas Ahmad Dahlan, sebagai salah satu institusi pendidikan yang memiliki komitmen untuk menghasilkan pendidikan yang bermutu, dapat melakukan pengukuran tingkat kepuasan pelanggannya dalam hal ini dari penilaian mahasiswa. analisis ini untuk menentukan apakah Universitas Ahmad Dahlan telah mampu memenuhi ketentuanketentuan yang diharapkan oleh pelanggannya khususnya mahasiswa.

Mutu pendidikan dapat dilihat dalam dua hal, yakni mengacu pada proses pendidikan dan hasil pendidikan. Proses pendidikan yang bermutu apabila seluruh komponen pendidikan terlibat dalam proses pendidikan itu sendiri. Faktor-faktor dalam proses pendidikan adalah berbagai input, seperti bahan ajar, metodologi, dukungan administrasi dan sarana prasarana, sumber daya lainnya serta penciptaan suasana kondusif. Sedangkan menurut Suryosubroto (2004)mutu pendidikan dalam konteks hasil pendidikan mengacu pada prestasi yang dicapai oleh sekolah pada setiap kurun waktu tertentu.

Menurut Kotler (1994) dalam Lupiyoadi (2009), Pelayanan adalah setiap tindakan atau kegiatan yang ditawarkan oleh suatu pihak kepada pihak lain, pada dasarnya tidak berwujud, dan tidak mengakibatkan kepemilikan apa pun. Menurut Lovelock dan Wright (2007) pelayanan adalah tindakan atau kinerja yang menciptakan manfaat bagi pelanggan dengan mewujudkan perubahan yang diinginkan dalam diri atau atas nama penerima.

Payne (2000) menyatakan jasa merupakan suatu kegiatan yang memiliki beberapa unsur ketidakberwujudan (intangibility) yang berhubungan dengannya, yang melibatkan beberapa interaksi dengan konsumen atau dengan properti dalam kepemilikannya, dan tidak 
menghasilkan transfer kepemilikan. Perubahan kondisi mungkin saja terjadi dan produksi jasa bisa saja berhubungan atau bisa pula tidak berkaitan dengan produk fisik.

Beberapa pengertian kepuasan pelanggan (customer satisfaction) dapat dilihat sebagai berikut: Kepuasan merupakan tingkat perasaan di mana seseorang menyatakan hasil perbandingan atas kinerja produk (jasa) yang diterima dan yang diharapkan (Kotler, 1997 dalam Lupiyoadi, 2009).

\section{METODE PENELITIAN}

Rancangan penelitian yang digunakan adalah deskriptif melalui observasi populatif dari mahasiswa Fakultas Farmasi Universitas Ahmad Dahlan Yogyakarta. Data dikumpulkan secara prospektif dan data kuantitatif diperoleh menggunakan alat penelitian berupa kuesioner .Hasil analisis secara deskriptif maupun kuantitatif kemudian digambarkan dalam bentuk tabel distribusi frekuensi responden, rata-rata penilaian per atribut dan per dimensi menurut tingkat harapan, kinerja, kepentingan dan kesenjangan (gap) pada setiap dimensi serta ratarata persepsi, ekspektasi dan Gap dari setiap dimensi.

\section{HASIL DAN PEMBAHASAN}

Pada bagian ini akan dibahas mengenai karakteristik responden yang digunakan dalam penelitian. Jumlah responden dalam penelitian sebanyak 212 mahasiswa. Data dari Biro Akademik dan Admisi Universitas Ahmad Dahlan diketahui bahwa jumlah mahasiswa aktif yang tercatat di tingkat akhir adalah 253 mahasiswa.

Dari data mengenai karakteristik responden akan dilihat keterkaitannya terhadap hasil penelitian mengenai kepuasan mahasiswa terhadap kualitas proses pelayanan pendidikan di Fakultas Farmasi Universitas Ahmad Dahlan Yogyakarta.

\section{a. Jenis Kelamin}

Dari hasil kuesioner yang telah diisi oleh responden didapatkan data sebaran jenis kelamin seperti pada Tabel 1.
Tabel I Klasifikasi responden di fakultas farmasi Universitas Ahmad Dahlan berdasarkan jenis kelamin

\begin{tabular}{cccc}
\hline No & $\begin{array}{c}\text { Jenis } \\
\text { kelamin }\end{array}$ & Jumlah & Persentase( \%) \\
\hline 1 & Laki laki & 47 & 22,16 \\
2 & Perempuan & 165 & 77,84 \\
\hline & & 212 & 100 \\
\hline
\end{tabular}

Dari data tersebut, diketahui bahwa jumlah responden atau mahasiswa perempuan lebih banyak daripada laki-laki, yaitu sebesar 77,84 \% responden adalah perempuan, dan 22,16\% responden adalah laki-laki dengan total responden sebanyak 212 mahasiswa.

Secara umum tidak ada perbedaan antara jenis kelamin pada penelitian ini dikarenakan mayoritas mahasiswa Fakultas Farmasi di Universitas Ahmad Dahlan adalah perempuan secara umum sudah diketahui bahwa jumlah mahasiswa perempuan di Fakultas Farmasi lebih banyak dari pada mahasiswa laki laki.

\section{b. Usia}

Usia rata rata responden mahasiswa ini adalah 19 hingga 21 tahun, karena responden yang digunakan dalam penelitian ini adalah mahasiswa tingkat akhir atau mahasiswa semester VII sehingga tidak ada variasi usia responden.

\section{c. Daerah Asal}

Dari hasil kuosioner diketahui bahwa mahasiswa sebagai responden di Fakultas Farmasi Universitas Ahmad Dahlan berasal dari seluruh Indonesia, persentase dan asal mahasiswa dapat dilihat dari Tabel 2.

Tabel II. Klasifikasi daerah asal responden di fakultas farmasi Universitas Ahmad Dahlan Yogyakarta

\begin{tabular}{clcc}
\hline No & Daerah asal & Jumlah & $\begin{array}{c}\text { Persentase } \\
\mathbf{( \% )}\end{array}$ \\
\hline 1 & P. Jawa & 108 & 50,95 \\
2 & P. Kalimantan & 46 & 21,70 \\
3 & P. Sumatra & 30 & 14,15 \\
4 & P. Sulawesi & 6 & 2.83 \\
5 & P. Papua & 0 & 0 \\
6 & Nusa Tengggara & 20 & 9,43 \\
7 & Ambon/Maluku & 2 & 0,94 \\
\hline \multicolumn{2}{r}{ Total } & $\mathbf{2 1 2}$ & $\mathbf{1 0 0 \%}$ \\
\hline
\end{tabular}


Dari sebaran asal responden diketahui lebih dari 50\% mahasiswa berasal dari Pulau Jawa dan responden yang berasal dari Ambon atau Maluku merupakan responden dengan jumlah terkecil yaitu kurang dari 1 \%Kualitas pelayanan yang dipersepsikan oleh mahasiswa Fakultas Farmasi Universitas X Yogyakarta dapat diketahui dari hasil membandingkan harapan dengan kinerja dari Fakultas Farmasi tersebut. Semakin tinggi kinerja Fakultas Farmasi Universitas Ahmad Dahlan dengan harapan pelanggan menunjukkan bahwa semakin tinggi kualitas pelayanan menurut persepsi pelanggan.Penilaian analisis kepuasan ini menggunakan analisis gap lima.

Gap lima dalam pelayanan adalah adanya gap yang terjadi antara harapan dengan kenyataan pelayanan yang diterima atau dirasakan mahasiswa di Fakultas Farmasi Universitas Ahmad Dahlan Yogyakarta. Secara ideal nilai gap antara harapan dan kinerja adalah 0 bahkan bernilai positif. Semakin besar nilai negatif suatu gap pada suatu dimensi pelayanan, semakin besar pula prioritas peningkatan pelayanan dimensi pelayanan tersebut.

\section{Analisis Kepuasan Pasien Berdasarkan Gap lima}

Gap lima dalam pelayanan adalah adanya gap yang terjadi antara harapan dengan kenyataan pelayanan yang diterima atau dirasakan mahasiswa di Fakultas Farmasi Universitas Ahmad Dahlan Yogyakarta. Idealnya nilai gap antara harapan dan kinerja adalah 0. Semakin besar nilai negatif suatu gap pada suatu dimensi pelayanan, semakin besar pula prioritas peningkatan pelayanan dimensi pelayanan tersebut.

Adapun hasil analisis gap di Fakultas Farmasi Universitas Ahmad Dahlan Yogyakarta adalah seperti yang terdapat pada Tabel III.

Gap yang diperoleh masing-masing dimensi menunjukkan tingkat harapan dan kinerja antara pelayanan yang diharapkan

Tabel III. Rerata kinerja, harapan dan nilai gap 5 serta peringkat gap setiap dimensi

\begin{tabular}{lcccc}
\hline Dimensi pelayanan & $\begin{array}{c}\text { Rerata nilai } \\
\text { harapan }\end{array}$ & $\begin{array}{c}\text { Rerata nilai } \\
\text { kinerja }\end{array}$ & Selisih & Peringkat \\
\hline Keandalan & 3,48 & 2,58 & $-0,90$ & 2 \\
Daya Tanggap & 3,77 & 2,63 & $-1,10$ & 5 \\
Jaminan & 3,56 & 2,63 & $-0,90$ & 3 \\
Empati & 3,60 & 2,50 & $-1,10$ & 4 \\
Berwujud & 3,60 & 2,70 & $-0,90$ & 1 \\
\hline
\end{tabular}

terhadap pelayanan yang diterima oleh mahasiswa yang pada akhirnya akan menentukan nilai kepuasan ataupun ketidakpuasan mahasiswa. Maksud nilai gap yang diperoleh dari penilaian lima dimensi kepuasan terhadap kinerja petugas pelayanan pendidikan pada karyawan adminstratif.

Pelanggan adalah raja, istilah ini sangat lazim didengar dan tidak berbeda dengan mahasiswa yang merupakan pelanggan di Perguruan Tinggi. Dalam pelaksanaan sehari hari istilah pelanggan adalah raja menjadi identik bahwa pelanggan merasa bahwa dirinya harus mendapatkan pelayanan yang terbaik dalam hal apa saja,termasuk kualitas layanan pendidikan.

Hasil penelitian dari Ramalu tahun 2011 terhadap 100 mahasiswa di salah satu univeritas
Malaysia diketahui bahwa dimensi SERVQUAL merupakan salah satu faktor utama yang menentukan kepuasan mahasiswa selama proses pendidikan. Keberhasilan pelayanan ini berpengaruh terhadap jumlah pendaftar mahasiswa pada Universitas tersebut. Penelitian Tan dan Kek pada tahun 2004 melakukan suatu analisa bahwa evaluasi kualias pelayanan di Lembaga Pendidikan Tinggi secara bermakna dapat dijadikan sebagai motivasi kerja serta umpan balik pada institusi pendidikan untuk mengelola kualitas pendidikan menjadi lebih baik.

Mahasiswa sebagai pelanggan atau konsumen dalam dunia pendidikan merasa bahwa segala sesuatu terkait dengan proses pendidikan harus dilayani dengan baik sesuai harapan 
mahasiswa. Sikap tersebut dapat membuat petugas pelayanan merasa tidak nyaman dan berdampak pelayanan yang diberikan tidak sesuai ketentuan institusi pendidikan. Pada umumnya konsumen atau pelanggan dalam hal ini adalah mahasiswa adalah sumber pendapatan utama dalam suatu lembaga pendidikan, alasan ini yang menjadi salah satu dasar bahwa mahasiswa harus dilayani dengan baik.

Mahasiswa sebagai konsumen atau pelanggan membayar manfaat yang diperoleh dari suatu lembaga yang memproduksi pelayanan pendidikan. Lembaga pendidikan yang mampu memahami dan memenuhi kebutuhan pelanggan atau konsumen akan mampu bertahan teradap persaingan. Karena pelayanan yang diberikan sesuai dengan keinginan mahasiswa. Mahasiswa yang merasa puas, maka akan muncul loyalitas yang baik dari mahasiswa tersebut.

Memahami karakteristik konsumen merupakan hal yang sangat penting. Tugas utama mahasiwa adalah belajar, salah satu faktor yang akan mempengaruhi tingkat keberhasilan belajar mahasiswa adalah apabila mahasiswa merasa nyaman dengan lingkungan disekitarnya termasuk lingkungan di lembaga pendidikan. Berbicara mengenai tingkat kualitas pelayanan pendidikan, maka muncul banyak jawaban dan akan muncul beberapa perbedaan berlainan dalam memahami, merasakan dan menilai apa yang dimaksud dengan kualitas pelayanan pendidikan. Terdapat beberapa hal yang sama berkaitan kualitas layanan pendidikan yang diharapkan oleh mahasiswa diantaranya adalah mahasiswa meniginkan kenyamanan dalam menggunakan seluruh layanan selama proses pendidikan. Mahasiswa juga mengharapkan tersedia seluruh fasilitas yang dapat menunjang proses pendidikannya. Mahasiswa mengharapkan sikap yang ramah, bersahabat dan responsif dari seluruh elemen petugas pelayanan.

Apabila terdapat kesesuaian antara harapan dan kenyataan yang diperoleh mahasiswa secara sederhana kualitas dirasakan pelayanan pendidikan sudah terpenuhi, akan tetapi dari hasil pengamatan yang dilakukan kualitas layanan pendidikan belum dirasakan dengan baik karena ada perbedaan gap antara harapan dan kenyataan yang dirasakan oleh mahasiswa.
Hasil pengamatan terhadap mahasiswa tersebut dapat digunakan dan diolah sebagai dasar perencanaan, pengambilan keputusan, pelaksanaan dan evaluasi guna perbaikan berkesinambungan (continuous Improvement) Agar sukses dan mampu bertahan dalam persaingan. Lembaga atau institusi pendidikan ini harus selalu melakukan perbaikan guna kepuasan konsumen dalam hal ini adalah mahasiwa.

\section{KESIMPULAN}

Berdasarkan penelitian yang telah dilakukan di Fakultas Farmasi Universitas Ahmad Dahlan Yogyakarta, maka dapat diambil kesimpulan sebagai berikut:

Secara umum pelayanan yang diberikan oleh karyawan belum ideal bagi mahasiswa dan belum memberikan kepuasan bagi mahasiswa. Nilai gap dari karyawan pada pelayanan pendidikan pada dimensi Berwujud (tangibles) dengan nilai gap -0,90, Keandalan (reliability) dengan nilai gap -0,90 , Jaminan (assurance) nilai gap -0,90, Empati (empathy) dengan nilai gap -1,10 dan Daya Tanggap (responsiveness) dengan nilai gap -1,10.

\section{SARAN}

Perlu peningkatan dan perbaikan secara keseluruhan dari elemen pelayanan pendidikan karena Kualitas pelayanan pendidikan hanya bisa diwujudkan berdasarkan kerja sama dari semua elemen pelayanan. Serta dilakukan evaluasi berkesinambungan dan achievement motivation sesuai dengan kebutuhan masing masing elemen pelayanan pendidikan baik karyawan, laboran maupun dosen agar dapat mempertahankan kinerja dari dimensi servqual yang sudah berjalan dengan baik dan dapat meningkatkan kinerja dari dimensi servqual yang belum dapat memberikan kepuasan bagi mahasiswa. Selain itu, perlu dilakukan penelitian mengenai aspek kepuasan mahasiswa terhadap kualitas layanan pendidikan di perguruan tinggi yang lain dengan responden yang berbeda.

\section{DAFTAR PUSTAKA}

Heizer, J., dan Render, B. 2005. Operational Management, Edisi Ketujuh, Penerbit Salemba Empat, Jakarta. 
Kotler, P. 2006. Manajemen Pemasaran, Edisi Kesebelas, Jilid I, Pretince Hall International Inc., New Jersey, 138, 245-246, 344, 372-373, 375-377.

Lovelock, H.C and Wright ,K.L. 2007. Manajemen Pemasaran Jasa., Alih Bahasa Agus Widyantoro cetakan kedua, PT. Indeks., Jakarta

Lupiyoadi. 2009. Manajemen Pemasaran Jasa,Teori dan Praktik, Edisi Kedua, Jakarta ,Salemba Empat.

Nurkholis,. 2003. Manajemen Berbasis Sekolah Teori dan Model Aplikasi, Jakarta, Gramedia Widiasarana Indonesia.
Payne. 2000. The Essence of Service Marketing, Edisi Kedua, Yogyakarta, Andi.

Ramalu W.C. 2011. Students Satisfaction Toward the University : Does Service QualityMatters?., International Journal of Education vol 3 no 2 diakses bulan Desember 2013

Suryosubroto B. 2004. Proses Belajar Mengajar di Sekolah., Rineka Cipta.,Jakarta

Tan Kay C,dkk.. 2004. Service Quality in Higher Education Using an Enhanched ServqualAproach., National University Of Singapore, Quality in Higher education Vol 10 no 1 April. Diakses Bulan Desember 2013. 